\title{
Isolated distal adductor magnus tendon avulsion as a rare cause of medial knee pain. A case report
}

\author{
Aamer lqbal, Shekhar Kalia1, David Beale², Steven L James, Rajesh Botchu \\ Department of Musculoskeletal Radiology, Royal Orthopaedic Hospital NHS Foundation Trust, Birmingham, UK, 'Sir Ganga Ram \\ Hospital, New Delhi, India, ${ }^{2}$ Heath Lodge Clinic, Knowle, UK
}

Correspondence: Dr Rajesh Botchu, Department of Musculoskeletal Radiology, The Royal Orthopedic Hospital, Bristol Road South, Northfield, Birmingham, UK. E-mail: drbrajesh@yahoo.com

\section{Abstract}

Avulsion injuries of adductor frequently involve the proximal origin. We report the first case of avulsion fracture of adductor magnus at its insertion and discuss the relevant anatomy.

Key words: Adductor; distal avulsion; magnus

\section{Introduction}

The adductor magnus is the largest and deepest medial thigh muscle. It is a fan-shaped muscle that is rarely injured. The adductor muscles are the second commonest muscle group to be injured after the hamstrings. Of these, the adductor longus is the most commonly injured muscle accounting for $62-90 \%$ of the cases. ${ }^{[1]}$ Avulsion injuries of the adductor muscles are uncommon and most frequently involve the proximal origin rather than the distal insertion. We present a case of avulsion fracture of the adductor tubercle at the distal adductor magnus insertion in a 20-yearold skier which is the first reported case in the literature.

\section{Case Report}

A 20-year-old male presented with medial right knee pain for a week following a fall whilst skiing. Clinically, the patient presented with a tender swelling on the medial aspect of the lower thigh and had an antalgic gait. MRI of

\begin{tabular}{|c|c|}
\hline \multicolumn{2}{|c|}{ Access this article online } \\
\hline Quick Response Code: & \\
\hline \multirow{2}{*}{ 回: } & $\begin{array}{l}\text { Website: } \\
\text { www.ijri.org }\end{array}$ \\
\hline & $\begin{array}{l}\text { DOI: } \\
\text { 10.4103/ijri.IJRI_523_19 }\end{array}$ \\
\hline
\end{tabular}

the right knee demonstrated a minimally displaced distal avulsion fracture of the adductor tubercle with diffuse marrow edema along the medial femoral condyle and a tear of the distal adductor magnus myotendinous junction [Figure 1]. The posteromedial corner of the knee was otherwise intact. The patient was conservatively managed.

\section{Discussion}

Lower limb injuries account for approximately $90 \%$ of all sports-related injuries ${ }^{[2]}$ and of these, involvement of the knee is relatively common. The menisci and ACL are most frequently injured. Avulsion injuries are relatively uncommon; however, their incidence continues to rise as the population becomes increasingly involved in sporting and other athletic activities. ${ }^{[3]}$ The knee is particularly susceptible to avulsion injuries due to the numerous ligamentous,

This is an open access journal, and articles are distributed under the terms of the Creative Commons Attribution-NonCommercial-ShareAlike 4.0 License, which allows others to remix, tweak, and build upon the work non-commercially, as long as appropriate credit is given and the new creations are licensed under the identical terms.

For reprints contact: WKHLRPMedknow_reprints@wolterskluwer.com

Cite this article as: Iqbal A, Kalia S, Beale D, James SL, Botchu R. Isolated distal adductor magnus tendon avulsion as a rare cause of medial knee pain. A case report. Indian J Radiol Imaging 2020;30:507-9.

Received: 03-Mar-2020 Accepted: 01-Sep-2020 Published: 13-Jan-2021 

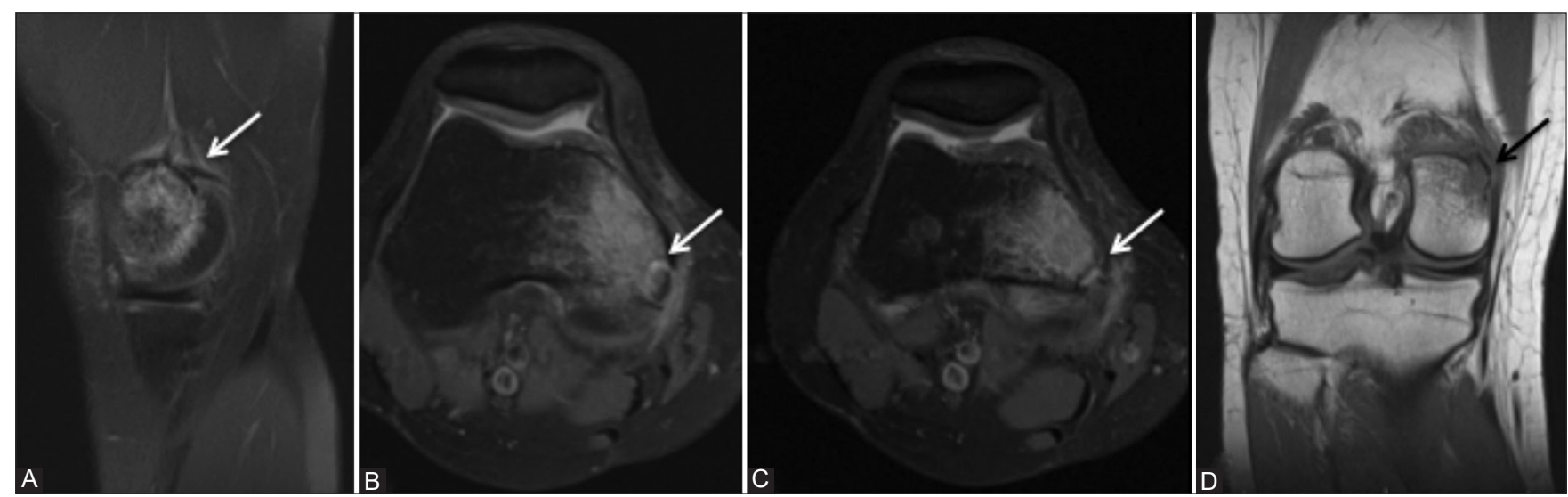

Figure 1 (A-D): STIR sagittal (A), axial (B and C), and T1 coronal (D) showing avulsion fracture (arrow) of the adductor tubercle at the site insertion of adductor magnus with marked osseous edema

tendinous, and meniscal attachments. The commonest avulsion injuries specific to the knee joint include the Segond fracture, reverse Segond fracture, cruciate ligament avulsion fractures, and ilio-tibial band avulsion fractures that rarely occur in isolation. Whilst proximal adductor magnus avulsion has previously been reported, isolated distal adductor magnus insertion avulsion injury is rare and the authors are not aware of any reported cases in the literature. Proximal adductor muscle strains and avulsions are more prevalent than distal injuries and most commonly occur in high-intensity kicking sports as a result of rapid uncoordinated movements. The adductor longus tendon is the commonest adductor muscle to be injured followed by the adductor magnus muscle. ${ }^{[4,5]}$ The exact mechanism of distal adductor magnus avulsion is unknown. Adductor insertion avulsion syndrome (AIAS) (thigh splints) is an uncommon osseous fatigue injury resulting from repetitive avulsive stresses at the tendinous insertion of the adductor longus and/or adductor brevis tendons onto the proximal and mid femur. ${ }^{[6]}$ The clinical presentation and imaging features of AIAS are different to avulsion injuries which have an acute onset. AIAS presents with vague activity-related groin pain that is relieved by rest. MRI demonstrates periosteal high signal on fluid-sensitive sequences along the insertion of the adductor longus and brevis tendons.

The medial knee has a relatively complex anatomy, which may preclude a diagnosis on radiographs or clinical examination and warrant an MRI. The adductor magnus is the most complex adductor muscle, which stabilizes the posteromedial compartment and plays a role in the flexion and extension movements of the hip joint. The muscle has pubofemoral and ischiofemoral heads [Figure 2]. The pubofemoral muscle fibers/adductor parts are directed horizontally that insert along the plane between the greater trochanter and linea aspera and are innervated by the posterior branch of the obturator nerve. The ischiofemoral fibers/hamstring part have vertical and lateral fibers that insert onto the linea aspera

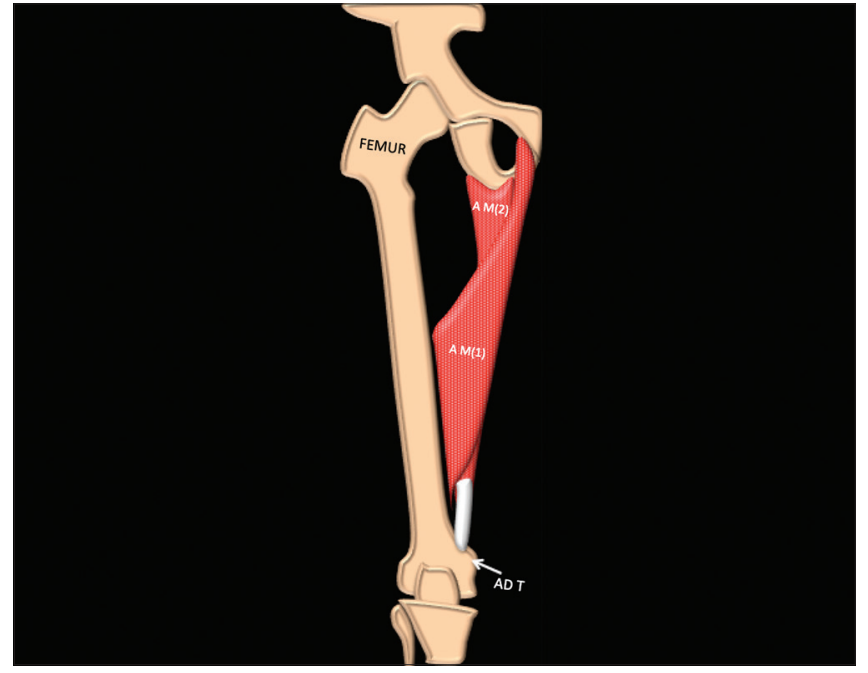

Figure 2: Coronal diagram showing the pubofemoral (AM1) and ischiocondylar (AM2) parts of adductor magnus. ADT (adductor tubercle)

and adductor tubercle ${ }^{[7]}$ and are innervated by the sciatic nerve. The adductor tubercle [AT] is a bony protuberance, situated just cranial to the medial epicondyle of femur and is the caudal most point of the medial supracondylar line serving as the insertion point of the ischiofemoral portion of the adductor magnus muscle..$^{[8,9]}$ The adductor magnus myotendinous junction occurs approximately at the level of the junction of the middle and distal thirds of the femur. As a result, the distal tendon has a long course to its insertion onto the adductor tubercle. On routine knee MRI, this tendon appears as a thin low signal structure on all sequences and is thus often overlooked.

There are multiple ligamentous and tendinous attachments in close proximity to the adductor magnus insertion onto the AT. The medial patellofemoral ligament (MPFL) attaches at a triangular area located anterior to the $\mathrm{AT} \cdot{ }^{[8,10]}$ The posterior oblique ligament originates slightly posteroinferiorly to the AT and is directed caudally, blending distally with the 


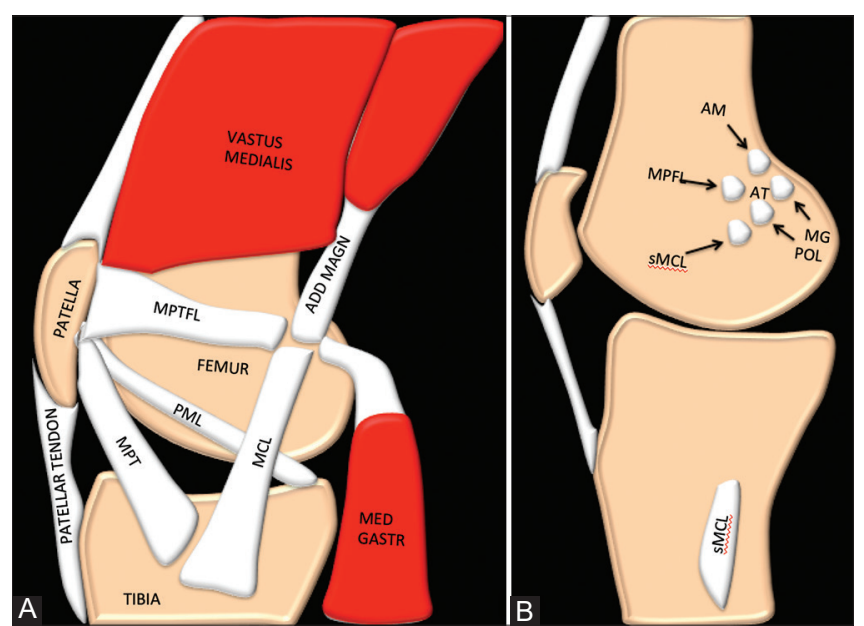

Figure 3 ( $A$ and $B$ ): Diagrams ( $A$ and $B$ ) of attachments of various structures in the medial aspect of the distal femora. MPT (medial patellotibial ligament), ADD MAGN (adductor magnus), MCL (medial collateral ligament), MED GAST (medial gastrocnemius), and SMCL (superficial MCL)

semimembranosus tendon. ${ }^{[9,11]}$ The gastrocnemius tubercle is located distal and posterior to AT, giving attachment to the medial head of gastrocnemius. ${ }^{[9,10]}$ The medial collateral ligament (MCL) arises from the medial epicondyle just distal to AT [Figure 3].

An avulsion fracture occurs when there is detachment of a bony fragment from the forces applied to a ligament, tendon, or joint capsule insertion onto the bone. Radiographically, a tiny osseous fragment located close to where the expected attachment of the ligament or tendon inserts maybe visualized. Other secondary signs including a joint effusion for intra-articular fractures or soft tissue swelling may also be present. Whilst computed tomography is useful in demonstrating the dimensions of the bony fragment, MRI is the modality of choice for knee injuries as it depicts the extent of both the bony and associated soft tissue injuries. In the context of distal adductor magnus avulsion, on MRI, the avulsed fragment should be visible with a small rim of fluid between the fragment and medial femoral condyle. Bone marrow edema maybe visualized in the medial femoral condyle. The adductor magnus tendon maybe unremarkable or torn to various degrees. There may be associated injuries to the remaining structures of the posteromedial corner such as the semimembranosus tendon, MCL, POL, and medial meniscus. ${ }^{[1]]}$ The likely mechanism of injury of the avulsion of distal adductor magnus is due to the forced eccentric contraction of the ischiofemoral ligament with knee in flexion.

\section{Summary}

Isolated adductor tubercle avulsion is a rare cause of medial knee pain in patients presenting with sport-related injuries.
Evaluation of the distal adductor magnus insertion is vital when assessing the posteromedial corner.

Declaration of patient consent

The authors certify that they have obtained all appropriate patient consent forms. In the form the patient(s) has/have given his/her/their consent for his/her/their images and other clinical information to be reported in the journal. The patients understand that their names and initials will not be published and due efforts will be made to conceal their identity, but anonymity cannot be guaranteed.

Financial support and sponsorship

Nil.

\section{Conflicts of interest}

There are no conflicts of interest.

\section{References}

1. Kiel J, Kaiser K. Adductor Strain. [Updated 2020 Jun 24]. In: StatPearls [Internet]. Treasure Island (FL): StatPearls Publishing; 2020 Jan-. Available from: https://www.ncbi.nlm.nih.gov/books/ NBK493166/.

2. Nicolini AP, Teixeira de Carvalho R, Matsuda MM, Filho JS, Cohen M. Common injuries in athletes' knee: Experience of a specialized center. Acta Ortop Bras 2014;22:127-31.

3. Gottsegen CJ, Eyer BA, White EA, Learch TJ, Forrester DM. Avulsion fractures of the knee: Imaging findings and clinical significance. Radiographics 2008;28:1755-70.

4. Werner J, Hägglund M, Waldén M, Ekstrand J. UEFA injury study: A prospective study of hip and groin injuries in professional football over seven consecutive seasons. Br J Sports Med 2009;43:1036-40.

5. Serner A, Weir A, Tol JL, Thorborg K, Roemer F, Guermazi A, et al. Characteristics of acute groin injuries in the adductor muscles: A detailed MRI study in athletes. Scand J Med Sci Sports 2018;28:667-76.

6. Anderson MW, Kaplan PA, Dussault RG. Adductor insertion avulsion syndrome (Thigh splints) spectrum of MR imaging findings. AJR Am J Roenterol 2001;177:673-5.

7. Jeno SH, Schindler GS. Anatomy, Bony Pelvis and Lower Limb, Thigh Adductor Magnus Muscles. [Updated 2018 Dec 16]. In: StatPearls [Internet]. Treasure Island (FL): StatPearls Publishing; 2019 Jan. Available from: https://www.ncbi.nlm.nih.gov/books/ NBK534842/.

8. Starok M, Lenchik L, Trudell D, Resnick D. Normal patellar retinaculum: MR and sonographic imaging with cadaveric correlation. AJR Am J Roentgenol 1997;168:1493-9.

9. LaPrade RF, Engebretsen AH, Ly TV, Johansen S, Wentorf FA, Engebretsen L. The anatomy of the medial part of the knee. J Bone Joint Surg Am 2007;89:2000-10.

10. Aframian A, Smith TO, Tennent TD, Cobb JP, Hing CB. Origin and insertion of the medial patellofemoral ligament: A systematic review of anatomy. Knee Surg Sports Traumatol Arthrosc 2017;25:3755-72.

11. Lundquist RB, Matcuk GR Jr, Schein AJ, Skalski MR, White EA, Forrester DM, et al. Posteromedial corner of the knee: The neglected corner. Radiographics 2015;35:1123-37. 